\title{
Synthesis of Poly(Propylene Fumarate)
}

\author{
F. Kurtis Kasper ${ }^{1}$, Kazuhiro Tanahashi ${ }^{1}$, John P. Fisher ${ }^{2}$, and Antonios G. Mikos ${ }^{1},{ }^{*}$ \\ ${ }^{1}$ Department of Bioengineering, Rice University, Houston, TX, USA \\ ${ }^{2}$ Fischell Department of Bioengineering, University of Maryland, College Park, MD, USA
}

\begin{abstract}
This protocol describes the synthesis of 500 - 4000 Da poly(propylene fumarate) by a two-step reaction of diethyl fumarate and propylene glycol through a bis(hydroxypropyl) fumarate diester intermediate. Purified PPF can be covalently crosslinked to form degradable polymer networks, which have been widely explored for biomedical applications. The properties of crosslinked PPF networks depend upon the molecular properties of the constituent polymer, such as the molecular weight. The purity of the reactants and the exclusion of water from the reaction system are of utmost importance in the generation of high-molecular-weight PPF products. Additionally, the reaction time and temperature influence the molecular weight of the PPF product. The expected time required to complete this protocol is $3 \mathrm{~d}$.
\end{abstract}

\section{Keywords}

biodegradable; biomaterial; injectable material; tissue engineering scaffold

\section{Introduction}

\section{Synthetic polymers for biomedical applications}

A number of different synthetic degradable polymers have been developed for biomedical applications ${ }^{1-6}$ (See Table 1). In general, these polymers have been developed for their physical properties, including degradation rate, degradation products, and mechanical strength, as well as the biological properties, including cell attachment, tissue ingrowth, and biocompatibility. For example, poly(glycolic acid) (PGA) is a linear aliphatic polyester formed by ring-opening polymerization of cyclic diesters of glycolide (See Table 1). PGA is hydrophilic and undergoes bulk degradation, often leading to a sudden loss in mechanical strength at some point during hydrolysis. Similar to PGA, poly(L-lactic acid) (PLLA) is a linear aliphatic polyester that is formed by ring-opening polymerization of L-lactide (See Table 1). PLLA typically undergoes bulk, hydrolytic ester-linkage degradation, decomposing into lactic acid, which can then be excreted by the body in the form of water and carbon dioxide via the respiratory system. The hydrophobic nature of PLLA allows for protein absorption and cell adhesion, making the polymer particularly useful in the fabrication of tissue scaffolds. Alternatively, poly( $\varepsilon$-caprolactone) (PCL) is an aliphatic polyester with semi-crystalline properties (See Table 1). PCL is highly water soluble with a melting temperature of approximately $60 \mathrm{oC}$. Degradation of PCL occurs by bulk or surface hydrolysis of its ester linkages, resulting in a byproduct of caproic acid. PCL degrades at a

\footnotetext{
*Corresponding Author: Antonios G. Mikos, Ph.D., Department of Bioengineering, Rice University, MS-142, P.O. Box 1892, Houston, Texas 77251-1892, Phone:(713) 348-5355, Fax: (713) 348-4244, mikos@ rice.edu.

Competing Interest Statement

The authors declare no competing financial interests.
} 
slow rate, persisting in vivo for up to two years, however PCL has been copolymerized with collagen, poly(glycolic acid), poly(lactic acid), and polyethylene oxide to increase its rate of degradation. Additional synthetic degradable polymers are presented in Table 1.

\section{Poly(propylene fumarate) and its applications}

Poly(propylene fumarate) (PPF) is a linear polyester based upon fumaric acid, a component of the Krebs cycle. The main advantages of PPF are (1) the unsaturated carbon-carbon bonds of the fumaric acid unit that allow for crosslinking of the polymer into a covalent polymer network, and (2) the formation of biocompatible and excretable degradation products, primarily fumaric acid and propylene glycol, upon hydrolysis of its ester linkages ${ }^{7-9}$. The principle disadvantage of PPF is that it is a viscous liquid at room temperature $\left(21^{\circ} \mathrm{C}\right)$, making handling of the polymer somewhat cumbersome.

Although crosslinked networks may be formed from PPF alone ${ }^{10}$, a variety of crosslinking agents have been explored in combination with PPF for the formation of crosslinked, degradable polymer networks with tunable material properties. For example, crosslinked networks of PPF with $N$-vinyl pyrrolidinone ${ }^{11}$, poly(ethylene glycol)-dimethacrylate ${ }^{12}$, PPF-diacrylate ${ }^{13}$, and diethyl fumarate ${ }^{14}$ have been developed. When combined with an appropriate initiator system, PPF-based polymer solutions are suitable for injectable applications in which they may be crosslinked in situ to form solid polymer networks. Due to the injectability, biocompatibility, and biodegradability of PPF-based polymers, they have been widely explored for a number of biomedical applications, such as the fabrication of orthopaedic implants ${ }^{15}$, scaffolds for tissue engineering ${ }^{16-20}$, controlled bioactive factor delivery systems ${ }^{21-26}$, and cell transplantation vehicles ${ }^{27,28}$ (See Table 2).

The properties of crosslinked PPF networks, including mechanical strength and biodegradation, are dependent upon the molecular characteristics of the constituent polymer 9,10,14,29,30. For instance, the molecular weight and polydispersity of PPF affects the mechanical strength and the degradation kinetics of crosslinked PPF networks ${ }^{31}$. Note that PPF molecular weights typically vary from $500-4000 \mathrm{Da}$, and polydispersities are generally below $1.4^{32}$. As PPF molecular weight increases, its viscosity also increases, often impacting the handling of the polymer and thus the intended applications ${ }^{14}$. For example, stereolithographic printing of PPF is generally improved with lower PPF molecular weights ${ }^{14,16}$. Additionally, the molecular weight of any crosslinking agents employed in the formation of a PPF-based network and the ratio of the crosslinking agent to PPF affect the degradation kinetics and mechanical strength of the resulting polymer network ${ }^{8}$. Accordingly, PPF-based polymer networks can be fabricated with a wide range of controllable properties as needed for specific applications through manipulation of tunable polymer parameters.

\section{Methods for synthesizing PPF}

A number of synthetic techniques for PPF have been reported ${ }^{32-34}$. For example, synthetic routes beginning with fumarates with highly reactive end groups, such as fumaryl chloride, have been described ${ }^{33,34}$. However, these routes have been associated with significant byproduct formation. More recently, the common method for synthesizing PPF follows a two-step procedure, beginning with diethyl fumarate and propylene glycol, and involving bis(hydroxypropyl) fumarate as an intermediate (See Figure 1). This is the current method of PPF synthesis that is employed in the authors' laboratory and the most recent synthesis procedure reported by the authors ${ }^{32}$. 


\section{Overview of the 2-step synthesis of PPF}

In the first step of the synthesis, diethyl fumarate and propylene glycol are reacted in an inert atmosphere in a molar ratio of $1: 3$, respectively. Additionally, $\mathrm{ZnCl}_{2}$ and hydroquinone are added as a catalyst and crosslinking inhibitor, respectively, in a 0.01: 0.002: 1 molar ratio to diethyl fumarate. The first step of the reaction occurs in a heated vessel under mechanical stirring, with a gradual increase in temperature from $110^{\circ} \mathrm{C}$ to $130^{\circ} \mathrm{C}$. This stage of the procedure results in the production of the bis(hydroxypropyl) fumarate intermediate and ethanol, which is collected as a distillate. This step of the reaction is terminated when approximately $90 \%$ of the theoretical yield of ethanol is collected.

The second step of the synthesis reaction involves transesterification of the bis(hydroxypropyl) fumarate intermediate to produce PPF. Here, the alkoxy group of bis(hydroxypropyl) fumarate is replaced with an alcohol from a second bis(hydroxypropyl) fumarate intermediate, propagating PPF polymerization and producing propylene glycol as a byproduct. This stage of the reaction is conducted under reduced pressure $(<1 \mathrm{~mm} \mathrm{Hg})$ and mechanical stirring, with a gradual increase in temperature from $100^{\circ} \mathrm{C}$ to $130^{\circ} \mathrm{C}$. The reaction proceeds until the desired molecular weight of PPF, as measured by gel permeation chromatography, is obtained.

Purification of the PPF product occurs through dissolution of the polymer in methylene chloride followed by several acid washes to remove the $\mathrm{ZnCl}_{2}$ catalyst. Further purification of the polymer solution involves two washes each with distilled water and brine. Sodium sulfate is then used to dry the organic polymer phase. Finally, the solvents are removed from the PPF solution through rotary evaporation and reduced pressure.

\section{Experimental Design}

This protocol describes the synthesis and purification of PPF through a two-step reaction of diethyl fumarate and propylene glycol to yield PPF through a bis(hydroxypropyl) fumarate diester intermediate ${ }^{32}$. The particular procedures described herein are appropriate for the synthesis of PPF for biomedical applications, such as the fabrication of biodegradable tissue engineering scaffolds and controlled bioactive factor delivery vehicles. High purity of the reactants and the exclusion of water from the reaction system are of critical importance to the production of high-molecular-weight polyesters in general, including PPF. Additionally, biomedical applications require the complete removal of organic solvents from the polymer product during the purification steps.

It should be noted that the procedure described herein is limited to the synthesis and purification of PPF. Due to the vast number of methods for PPF crosslinking, details for PPF crosslinking are not included in this protocol. However, a brief survey of the literature will reveal manuscripts describing several effective crosslinking methods $8,10-12,14$. Additionally, flexibility exists in several aspects of the procedure described in this manuscript. For example, the temperature and duration of the reaction may be adjusted to modulate the kinetics of the reaction and the molecular weight of the PPF product. Results have shown that PPF molecular weight may be varied from a low of 500 Da to a high of 4000 Da by altering reaction temperature and time ${ }^{32}$.

\section{Materials}

\section{Reagents}

- Brine solution

- Diethyl fumarate, 98\% (Sigma-Aldrich Co., cat. no. D95654-500G) 
Caution: Diethyl fumarate may be irritating and/or harmful if exposed to the skin or inhaled. All work should be conducted in a chemical fume hood. Personal protective equipment, including a lab coat, nitrile gloves, and safety glasses, should be worn when using diethyl fumarate.

- Ethyl ether (anhydrous), ACS certified, stabilized with BHT (Fisher Scientific, cat. no. E138-4)

- Hydrochloric acid (HCl), ACS certified (Fisher Scientific, cat. no. A144-212)

Caution: Hydrochloric acid may be irritating and/or harmful if exposed to the skin or inhaled. All work should be conducted in a chemical fume hood. Personal protective equipment, including a lab coat, acid resistant gloves, and safety glasses, should be worn when using hydrochloric acid.

- Hydroquinone, 99\% reagent plus (Sigma-Aldrich Co., cat. no. H1790-2)

- Methylene chloride, ACS certified, stabilized with amylene (Fisher Scientific, cat. no. D37-4)

- Nitrogen gas ( $\mathrm{N}_{2}(\mathrm{~g})$ ), ultra-high purity, $99.999 \%$ (Matheson Tri-Gas)

- $\quad$ Nitrogen liquid $\left(\mathrm{N}_{2}(\mathrm{l})\right)$ (Matheson Tri-Gas)

- Propylene glycol (1,2-propanediol) (PG) (Fisher Scientific, cat. no. P355-1)

Caution: Propylene glycol may be irritating and/or harmful exposed to the skin or inhaled. All work should be conducted in a chemical fume hood. Personal protective equipment, including a lab coat, nitrile gloves, and safety glasses, should be worn when using propylene glycol.

- Sodium sulfate (anhydrous, granular), >99.0\%, ACS certified (Fisher Scientific, cat. no. S421-3)

- Zinc chloride, 99.999\% (Sigma-Aldrich Co., cat. no. 229997-10G)

\section{Equipment}

- Aluminum foil

- $\quad$ Beaker $(250 \mathrm{ml})$

- Buchner funnel

- Clamp kecks for standard taper joints (Chemglass, cat. no. CG-145)

- Condenser

- Digital temperature monitor (Cole-Parmer)

- Distillation adapter $\left(75^{\circ}\right)$ (Chemglass, cat. no. CG-1024)

- Erlenmeyer flask (500 ml)

- Erlenmeyer flask (1-L)

- Erlenmeyer flask (2-L)

- Filter paper (Whatman \#40 Ashless Circles)

- Flow control adapter glass stopcock $\left(90^{\circ}\right)$ (Chemglass, cat. no. CG-1028)

- Gel permeation chromatography instrument (Waters 510 HPLC Pump equipped with a Waters Pump Control Module; Waters 717 Autosampler; Waters 486 Tunable Aborbance Detecter; Waters 410 Differential Refractometer) 
- Glass funnel

- Glass stoppers

- Graduated cylinder $(50 \mathrm{ml})$

- High vacuum pump (Fisher Scientific Maxima C Plus, cat. no. 01-257-8C)

- Ice bath

- Insulating wool

- Laboratory clamps

- Laboratory jacks

- $\quad$ Large magnetic stir bars (PTFE)

- Magnetic stir plate

- Mechanical vacuum stirrer assembly (EUROSTARpower-b, IKA Labortechnik) with a poly(tetrafluoroethylene) single-arc stirrer blade (19 mm width, $102 \mathrm{~mm}$ length)

- One-neck round-bottom flask (500 ml)

- $\quad$ One-neck round-bottom flask (1-L)

- $\quad$ Ring clamp

- Rotary evaporator (Büchi Rotavapor R-200, Büchi Vacuum Controller V-800, Büchi Vac V-500, Büchi Heating Bath B-490)

- Rubber tubing

- Separatory funnel (2-L) (Chemglass, cat. no. CG-1745)

- Silicon oil bath with heating mantle

- Thermometer

- $\quad$ Three-neck round-bottom flask (1-L)

- Vacuum gauge manometer

- Vacuum grease

- Vacuum take-off adapter (105) (Chemglass, cat. no. CG-1050)

- Vacuum trap (Chemglass, cat. no. CG-4514)

\section{Equipment Setup}

Preparation of glassware: Thoroughly clean and dry overnight (12 hr) all glassware for the apparatus (Figure 2$)$ in an oven $\left(100^{\circ} \mathrm{C}\right)$ then prepare the apparatus as shown.

Procedure-Production of Bis(hydroxypropyl) Fumarate Diester Intermediate (Steps $1-9$ should take approximately $12 \mathrm{~h}$ to complete)

1 Add diethyl fumarate (196.6 g, $1.14 \mathrm{~mol})$ and propylene glycol $(259.4 \mathrm{~g}, 3.41 \mathrm{~mol})$ into a three-neck round-bottomed flask ( 1 mol diethyl fumarate: 3 mol propylene glycol). Note that this protocol will produce approximately $140 \mathrm{~g}$ PPF.

Caution: Diethyl fumarate and propylene glycol may be irritating and/or harmful if exposed to the skin or inhaled. All work should be conducted in a chemical fume 
hood. Personal protective equipment, including a lab coat, nitrile gloves, and safety glasses, should be worn throughout the procedure.

2 Remove moisture from the system by establishing a purging flow of ultra-high purity nitrogen gas (no drying required).

Critical Step: The exclusion of water from the reaction system is essential to ensure the efficiency of the reaction. One may monitor the flow rate of nitrogen through the system by observing the nitrogen bubbles created in a water filled beaker (Fig. 2). A moderate flow rate ( 3 bubbles per second) of nitrogen increases the rate of ethanol removal from the system. However, an excessively high nitrogen flow rate (>10 bubbles per second) may result in undesired removal of volatile reactants, such as the diethyl fumarate.

3 Initiate stirring at approximately $150 \mathrm{rpm}$.

Caution: Ensure that the stirrer is set at $0 \mathrm{rpm}$ before switching on the unit, and then increase the speed slowly to approximately $150 \mathrm{rpm}$.

4 Add hydroquinone $\left(0.25 \mathrm{~g}, 2.3 \times 10^{-3} \mathrm{~mol}\right)$ and $\mathrm{ZnCl}_{2}\left(1.55 \mathrm{~g}, 1.1 \times 10^{-2} \mathrm{~mol}\right)$ into the three-neck round-bottomed reaction flask.

5 Establish flow of chilled water through the condenser and increase the stirring rate to $300 \mathrm{rpm}$.

6 Heat the flask in a silicone oil bath at $110^{\circ} \mathrm{C}$ for $30 \mathrm{~min}$.

7 Increase the temperature of the oil bath to $120^{\circ} \mathrm{C}$ for $30 \mathrm{~min}$ then to $130^{\circ} \mathrm{C}$.

8 Continue the reaction at $130^{\circ} \mathrm{C}$ until approximately $90 \%$ of the theoretical yield of ethanol has been collected in the receiving flask (approximately $95 \mathrm{~g}$ of the theoretical $105 \mathrm{~g}$ ).

\section{TROUBLESHOOTING}

Critical Step: The reaction generally requires 6 to $8 \mathrm{~h}$. The time required for the reaction may be decreased by increasing the temperature of the oil bath, increasing the stirring rate, and/or increasing the flow rate of the nitrogen gas. However, one should avoid temperatures above $150^{\circ} \mathrm{C}$ to mitigate potential side reactions ${ }^{32}$. High flow rates of nitrogen gas should likewise be avoided as previously mentioned.

9 Once the desired amount of ethanol has been collected, cool the reaction flask to room temperature $\left(25^{\circ} \mathrm{C}\right)$ with a continued flow of nitrogen gas through the system.

Pause Point: Once cooled, the reaction products may be sealed and stored overnight in the fume hood, if needed.

Transesterification Reaction (Steps $10-20$ should take approximately $9 \mathrm{~h}$ to complete)

10 Reassemble the apparatus as in the first reaction using the three-neck roundbottom flask containing the bis(hydroxypropyl) fumarate diester intermediate.

11 Initiate flow of the purging nitrogen gas through the apparatus and of the chilled water through the condenser.

12 Initiate stirring of the diester intermediate at a rate of $300 \mathrm{rpm}$.

13 Heat the flask in a silicone oil bath at $100^{\circ} \mathrm{C}$ for $30 \mathrm{~min}$.

14 Stop the nitrogen gas purge and replace the gas outlet house attached to the vacuum take-off adapter with a hose connected to a high vacuum apparatus. 
Caution: The vacuum apparatus should be equipped with a liquid nitrogen cooled vacuum trap to collect potentially harmful volatile compounds.

15 Reduce the pressure in the system to less than $1 \mathrm{mmHg}$.

Caution: Reduce the pressure in the system slowly to avoid rapid boiling of propylene glycol and consequent displacement of reactants out of the reaction flask.

16 Increase the temperature of the oil bath to $110^{\circ} \mathrm{C}$ for $30 \mathrm{~min}$.

17 Increase the temperature of the oil bath to $120^{\circ} \mathrm{C}$ for $30 \mathrm{~min}$.

18 Increase the temperature of the oil bath to $130^{\circ} \mathrm{C}$.

\section{TROUBLESHOOTING}

Critical Step: The extent of transesterification and the molecular weight of the resulting PPF increase with reaction time. Consequently, the molecular weight of the PPF should be monitored regularly (e.g., every half hour or hour) during the reaction using a gel permeation chromatography column. Samples may be removed periodically from the reaction vessel using a Pasteur pipette. Note that the purification procedure for the PPF product removes some of the lower molecular weight polymer chains, thereby increasing the average molecular weight of the polymer. As a result, the average molecular weight of the polymer following purification will typically be higher (approximately $300-400 \mathrm{Da}$ ) than the value measured during the monitoring of the reaction.

19 Terminate the reaction and allow the system to cool to room temperature under a purge of nitrogen gas when the desired molecular weight has been achieved (accounting for the change in average molecular weight in the purification procedure).

\section{TROUBLESHOOTING}

20 Add methylene chloride (approximately $300 \mathrm{ml}$ ) to the polymer product in the reaction flask and purge the system with nitrogen gas.

Pause Point: The cooled reaction products may be sealed and stored overnight at $21^{\circ} \mathrm{C}$ in the fume hood, if needed.

Purification of Poly(propylene fumarate): Aqueous Washes (Steps 21 - 31 should take approximately $6 \mathrm{~h}$ to complete)

21 Add additional methylene chloride (approximately $300 \mathrm{ml}$ ) to the polymer solution to bring the total solution volume to approximately $800 \mathrm{ml}$.

22 Transfer the polymer solution into a 2-L separatory funnel positioned in a ring clamp above a 2-L Ernlenmeyer flask.

23 Add a volume of $1.85 \%$ (vol/ $/ \mathrm{vol}) \mathrm{HCl}$ solution approximately equal to the volume of the polymer solution (approximately $800 \mathrm{ml}$ ) to the separatory funnel, such that the acid and polymer solutions are at a volume ratio of $1: 1$. Mark the interface between the solutions on the outside of the separatory funnel.

Caution: Hydrochloric acid may be irritating and/or harmful if exposed to the skin or inhaled. All work should be conducted in a chemical fume hood. Personal protective equipment, including a lab coat, acid resistant gloves, and safety glasses, should be worn throughout the procedure. 
24 Cap and invert the separatory funnel then open the stopcock to vent gas while the funnel is inverted.

25 Close the stopcock, briefly shake the funnel to agitate the solution, invert the funnel, and open the stopcock to vent liberated gas.

26 Repeat the shaking/venting step (Step 25) several times, increasing the amount of shaking each time.

27 Close the stopcock, shake the solution vigorously, then place the separatory funnel on the ring stand and open the cap of the funnel.

28 Allow the phases to separate for approximately $10 \mathrm{~min}$. One may use the mark made at the interface between the phases in Step 23 to facilitate visualization of the two separate phases (Fig. 3(A)).

29 Collect the polymer phase (the bottom phase) into a 2-L Erlenmeyer flask and appropriately discard the aqueous phase.

\section{TROUBLESHOOTING}

Critical Step: The polymer solution should appear cloudy at this point (Fig. 3(B)).

30 Repeat the wash procedure (Steps 22 through 29) twice using double-distilled $\mathrm{H}_{2} \mathrm{O}$ instead of the $1.85 \%$ ( $\left.\mathrm{vol} / \mathrm{vol}\right) \mathrm{HCl}$ solution.

Critical Step: Rinse the separatory funnel and the 2-L collection flask with acetone between each wash cycle.

Critical Step: In the event that the separation of the phases becomes too difficult to discern, then add a small amount of brine to the aqueous phase after shaking. The polymer solution should appear milky white following the $1^{\text {st }}$ wash with $\mathrm{H}_{2} \mathrm{O}$.

31 Repeat the wash procedure (Steps 22 through 29) twice using brine solution instead of the $1.85 \%$ ( vol/vol) $\mathrm{HCl}$ solution.

Critical Step: The collected polymer solution should be turbid with a light yellow color following the brine washes.

Purification of Poly(propylene fumarate): Drying with Sodium Sulfate (Steps 32 - 37 should take approximately $6 \mathrm{~h}$ to complete)

32 Stir the polymer solution using a magnetic stir bar.

33 Slowly add sodium sulfate to the polymer solution under stirring until small aggregates of sodium sulfate are apparent and the polymer solution becomes transparent with a light yellow color.

34 Cap or cover the flask and allow the solution to stir for $30 \mathrm{~min}$.

35 Vacuum filter the solution using a Buchner funnel with filter paper (Whatman \#40 Ashless Circles) to remove the sodium sulfate.

36 Transfer the polymer solution filtrate into a 1-L round-bottom flask.

Critical step: In order to minimize the potential for boiling-over in the evaporation in Step 37, do not fill the flask more than 2/3 of capacity. Any remaining polymer solution may be added to the flask at a pause point in the rotary evaporation procedure. 
37 Remove methylene chloride through reduced pressure and rotation using a rotary evaporator with an associated heated water bath $\left(40^{\circ} \mathrm{C}\right)$.

Critical Step: When the volume of solution in the flask has been reduced through evaporation of the methylene chloride, additional polymer solution (if any) may be added and the procedure continued.

Purification of Poly(propylene fumarate): Ether Washes (Steps 38 - 40 should take approximately $3 \mathrm{~h}$ to complete)

38 Prepare 1-L of ethyl ether in a 2-L Erlenmeyer flask cooled with an ice bath.

39 While stirring the ethyl ether with a magnetic stirrer, slowly pour the polymer solution from step 37 into the ethyl ether.

Critical step: The ether solution will become white in appearance and the polymer will appear as a yellow precipitate.

40 Upon complete addition of the polymer solution, stop the stirring and decant the ether phase into an appropriate container for disposal.

Purification of Poly(propylene fumarate): Solvent Removal (Steps 41 - 44 should take approximately $3 \mathrm{~h}$ to complete)

41 Dissolve the polymer product from step 40 in methylene chloride $(300 \mathrm{ml})$.

42 Remove methylene chloride from the polymer solution through rotary evaporation at reduced pressure using a rotary evaporator with an associated heated water bath $\left(40^{\circ} \mathrm{C}\right)$.

43 Complete drying of the polymer product under high vacuum at room temperature for at least $8 \mathrm{~h}$.

Caution: The vacuum apparatus should be equipped with a liquid nitrogen cooled vacuum trap to collect potentially harmful volatile compounds.

44 Vacuum-evacuate the flask and purge with nitrogen gas.

Pause Point: Store the polymer product at $4^{\circ} \mathrm{C}$ for up to 3 months.

Determination of Molecular Weight of Poly(propylene fumarate) (Step 45 should take approximately $6 \mathrm{~h}$ to complete)

45 Determine the molecular weight of the PPF product using gel permeation chromatography (GPC) at $25^{\circ} \mathrm{C}$ using a GPC column (Waters, Styragel HR 4E, $7.8 \times 300 \mathrm{~mm}$ column $(50-100000 \mathrm{Da}$ range) $)$ at a flow rate of $1.0 \mathrm{ml} / \mathrm{min}$ with degassed chloroform as the eluent. For systems using a refractive index detector, the molecular weight distributions should be determined relative to a calibration curve generated from polystyrene standards $\left(M_{n}=500,2630,5970\right.$, and 9100 $\mathrm{Da})$.

Timing-Synthesis of PPF: Steps 1-9, $12 \mathrm{~h}$; Steps $10-20,9 \mathrm{~h}$.

Purification of PPF: Steps 21 -31, 6 h; Steps $32-37,6$ h; Steps 38 - 40, 3 h; Steps 41 - 44, $3 \mathrm{~h}$.

Determination of molecular weight: Step 45, $6 \mathrm{~h}$.

Troubleshooting-Troubleshooting advice can be found in Table 3. 


\section{Anticipated Results}

Typical yields: Typical isolated yields are greater than approximately $350 \mathrm{~g}$ of poly(propylene fumarate) per $500 \mathrm{~g}$ of diethyl fumarate reactant.

PPF: A typical ${ }^{1} \mathrm{H}$ NMR (400 MHz, $\mathrm{CDCl}_{3}$, ambient temperature) spectrum for PPF is shown in Figure 4. Number average molecular weight $\left(M_{n}\right)$ relative to polystyrene standards: approximately $500-4000 \mathrm{Da}$, depending upon reaction conditions ${ }^{32}$.

\section{Acknowledgments}

The work described in this protocol was supported by grants from the US National Institutes of Health to A.G.M. (R01 DE15164 and R01 DE17441).

\section{References}

1. Coombes DM, Shelley MJ, McKenzie J, Sneddon KJ. Biodegradable fixation in oral and maxillofacial surgery. Dent Update. 2007; 34:641-644. [PubMed: 18196829]

2. Guelcher SA. Biodegradable polyurethanes: synthesis and applications in regenerative medicine. Tissue Eng Part B Rev. 2008; 14:3-17. [PubMed: 18454631]

3. Houchin ML, Topp EM. Chemical degradation of peptides and proteins in PLGA: a review of reactions and mechanisms. J Pharm Sci. 2008; 97:2395-2404. [PubMed: 17828756]

4. Hutmacher DW, Schantz JT, Lam CX, Tan KC, Lim TC. State of the art and future directions of scaffold-based bone engineering from a biomaterials perspective. J Tissue Eng Regen Med. 2007; 1:245-260. [PubMed: 18038415]

5. Tsuji H. Poly(lactide) stereocomplexes: formation, structure, properties, degradation, and applications. Macromol Biosci. 2005; 5:569-597. [PubMed: 15997437]

6. Venugopal J, Low S, Choon AT, Ramakrishna S. Interaction of cells and nanofiber scaffolds in tissue engineering. J Biomed Mater Res B Appl Biomater. 2008; 84:34-48. [PubMed: 17477388]

7. Fisher JP, Holland TA, Dean D, Mikos AG. Photoinitiated cross-linking of the biodegradable polyester poly(propylene fumarate). Part II. In vitro degradation. Biomacromolecules. 2003; 4:1335-1342. [PubMed: 12959603]

8. Timmer MD, Ambrose CG, Mikos AG. In vitro degradation of polymeric networks of poly(propylene fumarate) and the crosslinking macromer poly(propylene fumarate)-diacrylate. Biomaterials. 2003; 24:571-577. [PubMed: 12437951]

9. Timmer MD, Ambrose CG, Mikos AG. Evaluation of thermal- and photo-crosslinked biodegradable poly(propylene fumarate)-based networks. J Biomed Mater Res A. 2003; 66:811-818. [PubMed: 12926033]

10. Fisher JP, Holland TA, Dean D, Engel PS, Mikos AG. Synthesis and properties of photocrosslinked poly(propylene fumarate) scaffolds. J Biomater Sci Polym Ed. 2001; 12:673-687. [PubMed: 11556743]

11. Peter SJ, Kim P, Yasko AW, Yaszemski MJ, Mikos AG. Crosslinking characteristics of an injectable poly(propylene fumarate)/beta-tricalcium phosphate paste and mechanical properties of the crosslinked composite for use as a biodegradable bone cement. J Biomed Mater Res. 1999; 44:314-321. [PubMed: 10397934]

12. He S, Yaszemski MJ, Yasko AW, Engel PS, Mikos AG. Injectable biodegradable polymer composites based on poly(propylene fumarate) crosslinked with poly(ethylene glycol)dimethacrylate. Biomaterials. 2000; 21:2389-2394. [PubMed: 11055286]

13. He S, et al. Synthesis of biodegradable poly(propylene fumarate) networks with poly(propylene fumarate)-diacrylate macromers as crosslinking agents and characterization of their degradation products. Polymer. 2001; 42:1251-1260.

14. Fisher JP, Dean D, Mikos AG. Photocrosslinking characteristics and mechanical properties of diethyl fumarate/poly(propylene fumarate) biomaterials. Biomaterials. 2002; 23:4333-4343. [PubMed: 12219823] 
15. Timmer MD, Carter C, Ambrose CG, Mikos AG. Fabrication of poly(propylene fumarate)-based orthopaedic implants by photo-crosslinking through transparent silicone molds. Biomaterials. 2003; 24:4707-4714. [PubMed: 12951014]

16. Cooke MN, Fisher JP, Dean D, Rimnac C, Mikos AG. Use of stereolithography to manufacture critical-sized 3D biodegradable scaffolds for bone ingrowth. J Biomed Mater Res B Appl Biomater. 2003; 64:65-69. [PubMed: 12516080]

17. Dean D, et al. Poly(propylene fumarate) and poly(DL-lactic-co-glycolic acid) as scaffold materials for solid and foam-coated composite tissue-engineered constructs for cranial reconstruction. Tissue Eng. 2003; 9:495-504. [PubMed: 12857417]

18. Dean D, et al. Effect of transforming growth factor beta 2 on marrow-infused foam poly(propylene fumarate) tissue-engineered constructs for the repair of critical-size cranial defects in rabbits. Tissue Eng. 2005; 11:923-939. [PubMed: 15998232]

19. Fisher JP, et al. Soft and hard tissue response to photocrosslinked poly(propylene fumarate) scaffolds in a rabbit model. J Biomed Mater Res. 2002; 59:547-556. [PubMed: 11774313]

20. Hedberg EL, et al. Methods: a comparative analysis of radiography, microcomputed tomography, and histology for bone tissue engineering. Tissue Eng. 2005; 11:1356-1367. [PubMed: 16259591]

21. Hacker MC, et al. Biodegradable fumarate-based drug-delivery systems for ophthalmic applications. J Biomed Mater Res A. 2008

22. Haesslein A, Hacker MC, Mikos AG. Effect of macromer molecular weight on in vitro ophthalmic drug release from photo-crosslinked matrices. Acta Biomater. 2008; 4:1-10. [PubMed: 17938009]

23. Haesslein A, et al. Long-term release of fluocinolone acetonide using biodegradable fumaratebased polymers. J Control Release. 2006; 114:251-260. [PubMed: 16872709]

24. Hedberg EL, et al. Effect of varied release kinetics of the osteogenic thrombin peptide TP508 from biodegradable, polymeric scaffolds on bone formation in vivo. J Biomed Mater Res A. 2005; 72:343-353. [PubMed: 15666357]

25. Hedberg EL, Tang A, Crowther RS, Carney DH, Mikos AG. Controlled release of an osteogenic peptide from injectable biodegradable polymeric composites. J Control Release. 2002; 84:137150. [PubMed: 12468217]

26. Ueda $\mathrm{H}$, et al. Injectable, in situ forming poly(propylene fumarate)-based ocular drug delivery systems. J Biomed Mater Res A. 2007; 83:656-666. [PubMed: 17514745]

27. Payne RG, McGonigle JS, Yaszemski MJ, Yasko AW, Mikos AG. Development of an injectable, in situ crosslinkable, degradable polymeric carrier for osteogenic cell populations. Part 3. Proliferation and differentiation of encapsulated marrow stromal osteoblasts cultured on crosslinking poly(propylene fumarate). Biomaterials. 2002; 23:4381-4387. [PubMed: 12219828]

28. Payne RG, McGonigle JS, Yaszemski MJ, Yasko AW, Mikos AG. Development of an injectable, in situ crosslinkable, degradable polymeric carrier for osteogenic cell populations. Part 2. Viability of encapsulated marrow stromal osteoblasts cultured on crosslinking poly(propylene fumarate). Biomaterials. 2002; 23:4373-4380. [PubMed: 12219827]

29. Porter BD, et al. Mechanical properties of a biodegradable bone regeneration scaffold. J Biomech Eng. 2000; 122:286-288. [PubMed: 10923298]

30. Timmer MD, Horch RA, Ambrose CG, Mikos AG. Effect of physiological temperature on the mechanical properties and network structure of biodegradable poly(propylene fumarate)-based networks. J Biomater Sci Polym Ed. 2003; 14:369-382. [PubMed: 12747675]

31. Domb AJ, Cato TL, Israeli O, Gerhart TN, Langer R. The formation of propylene fumarate oligomers for use in bioerodible bone cement composites. J Polym Sci A. 1990; 28:973-985.

32. Shung AK, Timmer MD, Jo S, Engel PS, Mikos AG. Kinetics of poly(propylene fumarate) synthesis by step polymerization of diethyl fumarate and propylene glycol using zinc chloride as a catalyst. J Biomater Sci Polym Ed. 2002; 13:95-108. [PubMed: 12003078]

33. Peter SJ, Suggs LJ, Yaszemski MJ, Engel PS, Mikos AG. Synthesis of poly(propylene fumarate) by acylation of propylene glycol in the presence of a proton scavenger. J Biomater Sci Polym Ed. 1999; 10:363-373. [PubMed: 10189104]

34. Peter SJ, et al. Characterization of partially saturated poly(propylene fumarate) for orthopaedic application. J Biomater Sci Polym Ed. 1997; 8:893-904. [PubMed: 9342654] 
35. Peter SJ, Lu L, Kim DJ, Mikos AG. Marrow stromal osteoblast function on a poly(propylene fumarate)/beta-tricalcium phosphate biodegradable orthopaedic composite. Biomaterials. 2000; 21:1207-1213. [PubMed: 10811302]

36. Peter SJ, et al. Effects of transforming growth factor beta1 released from biodegradable polymer microparticles on marrow stromal osteoblasts cultured on poly(propylene fumarate) substrates. J Biomed Mater Res. 2000; 50:452-462. [PubMed: 10737888]

37. Peter SJ, Miller ST, Zhu G, Yasko AW, Mikos AG. In vivo degradation of a poly(propylene fumarate)/beta-tricalcium phosphate injectable composite scaffold. J Biomed Mater Res. 1998; 41:1-7. [PubMed: 9641618]

38. Fisher JP, et al. Effect of biomaterial properties on bone healing in a rabbit tooth extraction socket model. J Biomed Mater Res A. 2004; 68:428-438. [PubMed: 14762922]

39. Fisher JP, et al. Photoinitiated cross-linking of the biodegradable polyester poly(propylene fumarate). Part I. Determination of network structure. Biomacromolecules. 2003; 4:1327-1334. [PubMed: 12959602]

40. Christenson EM, Soofi W, Holm JL, Cameron NR, Mikos AG. Biodegradable fumarate-based polyHIPEs as tissue engineering scaffolds. Biomacromolecules. 2007; 8:3806-3814. [PubMed: 17979240]

41. Hedberg EL, et al. In vivo degradation of porous poly(propylene fumarate)/poly(DL-lactic-coglycolic acid) composite scaffolds. Biomaterials. 2005; 26:4616-4623. [PubMed: 15722131]

42. Hedberg EL, et al. In vitro degradation of porous poly(propylene fumarate)/poly(DL-lactic-coglycolic acid) composite scaffolds. Biomaterials. 2005; 26:3215-3225. [PubMed: 15603816]

43. Horch RA, et al. Nanoreinforcement of poly(propylene fumarate)-based networks with surface modified alumoxane nanoparticles for bone tissue engineering. Biomacromolecules. 2004; 5:1990-1998. [PubMed: 15360315]

44. Shi X, et al. In vitro cytotoxicity of single-walled carbon nanotube/biodegradable polymer nanocomposites. J Biomed Mater Res A. 2007

45. Shi X, et al. Injectable nanocomposites of single-walled carbon nanotubes and biodegradable polymers for bone tissue engineering. Biomacromolecules. 2006; 7:2237-2242. [PubMed: 16827593]

46. Shi X, et al. Fabrication of porous ultra-short single-walled carbon nanotube nanocomposite scaffolds for bone tissue engineering. Biomaterials. 2007; 28:4078-4090. [PubMed: 17576009]

47. Suggs LJ, et al. Preparation and characterization of poly(propylene fumarate-co-ethylene glycol) hydrogels. J Biomater Sci Polym Ed. 1998; 9:653-666. [PubMed: 9686333]

48. Suggs LJ, et al. In vitro and in vivo degradation of poly(propylene fumarate-co-ethylene glycol) hydrogels. J Biomed Mater Res. 1998; 42:312-320. [PubMed: 9773828]

49. Suggs LJ, Mikos AG. Development of poly(propylene fumarate-co-ethylene glycol) as an injectable carrier for endothelial cells. Cell Transplant. 1999; 8:345-350. [PubMed: 10478714]

50. Suggs LJ, Shive MS, Garcia CA, Anderson JM, Mikos AG. In vitro cytotoxicity and in vivo biocompatibility of poly(propylene fumarate-co-ethylene glycol) hydrogels. J Biomed Mater Res. 1999; 46:22-32. [PubMed: 10357132]

51. Suggs LJ, West JL, Mikos AG. Platelet adhesion on a bioresorbable poly(propylene fumarate-coethylene glycol) copolymer. Biomaterials. 1999; 20:683-690. [PubMed: 10208411]

52. Shung AK, Behravesh E, Jo S, Mikos AG. Crosslinking characteristics of and cell adhesion to an injectable poly(propylene fumarate-co-ethylene glycol) hydrogel using a water-soluble crosslinking system. Tissue Eng. 2003; 9:243-254. [PubMed: 12740087]

53. Behravesh E, Jo S, Zygourakis K, Mikos AG. Synthesis of in situ cross-linkable macroporous biodegradable poly(propylene fumarate-co-ethylene glycol) hydrogels. Biomacromolecules. 2002; 3:374-381. [PubMed: 11888325]

54. Behravesh E, Mikos AG. Three-dimensional culture of differentiating marrow stromal osteoblasts in biomimetic poly(propylene fumarate-co-ethylene glycol)-based macroporous hydrogels. J Biomed Mater Res A. 2003; 66:698-706. [PubMed: 12918054]

55. Behravesh E, Timmer MD, Lemoine JJ, Liebschner MA, Mikos AG. Evaluation of the in vitro degradation of macroporous hydrogels using gravimetry, confined compression testing, and microcomputed tomography. Biomacromolecules. 2002; 3:1263-1270. [PubMed: 12425664] 
56. Behravesh E, Zygourakis K, Mikos AG. Adhesion and migration of marrow-derived osteoblasts on injectable in situ crosslinkable poly(propylene fumarate-co-ethylene glycol)-based hydrogels with a covalently linked RGDS peptide. J Biomed Mater Res A. 2003; 65:260-270. [PubMed: 12734821]

57. Jo S, Shin H, Mikos AG. Modification of oligo(poly(ethylene glycol) fumarate) macromer with a GRGD peptide for the preparation of functionalized polymer networks. Biomacromolecules. 2001; 2:255-261. [PubMed: 11749181] 

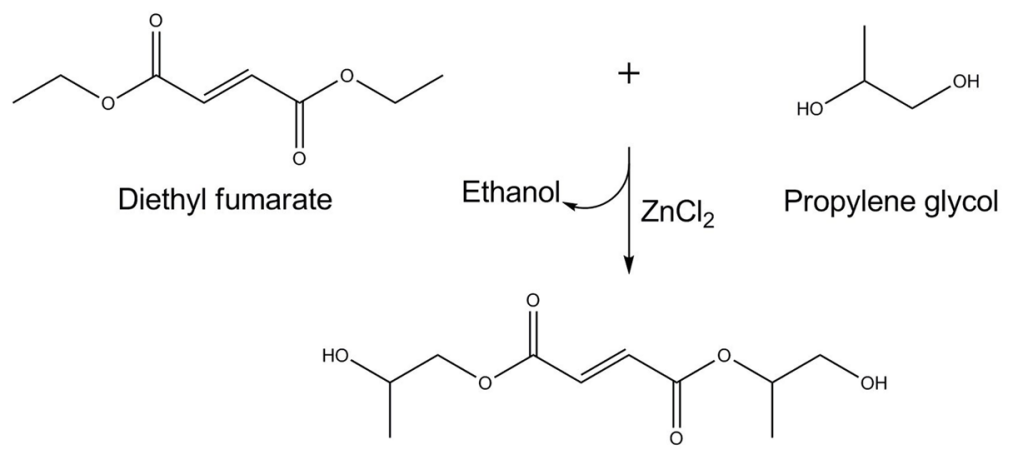

Bis(hydroxypropyl) fumarate

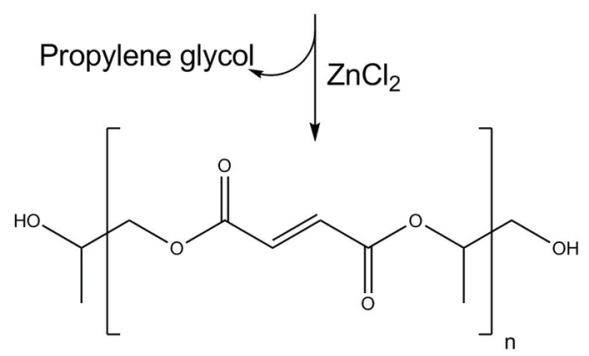

Poly(propylene fumarate)

Figure 1.

Two-step synthesis of poly(propylene fumarate) from diethyl fumarate and propylene glycol. 


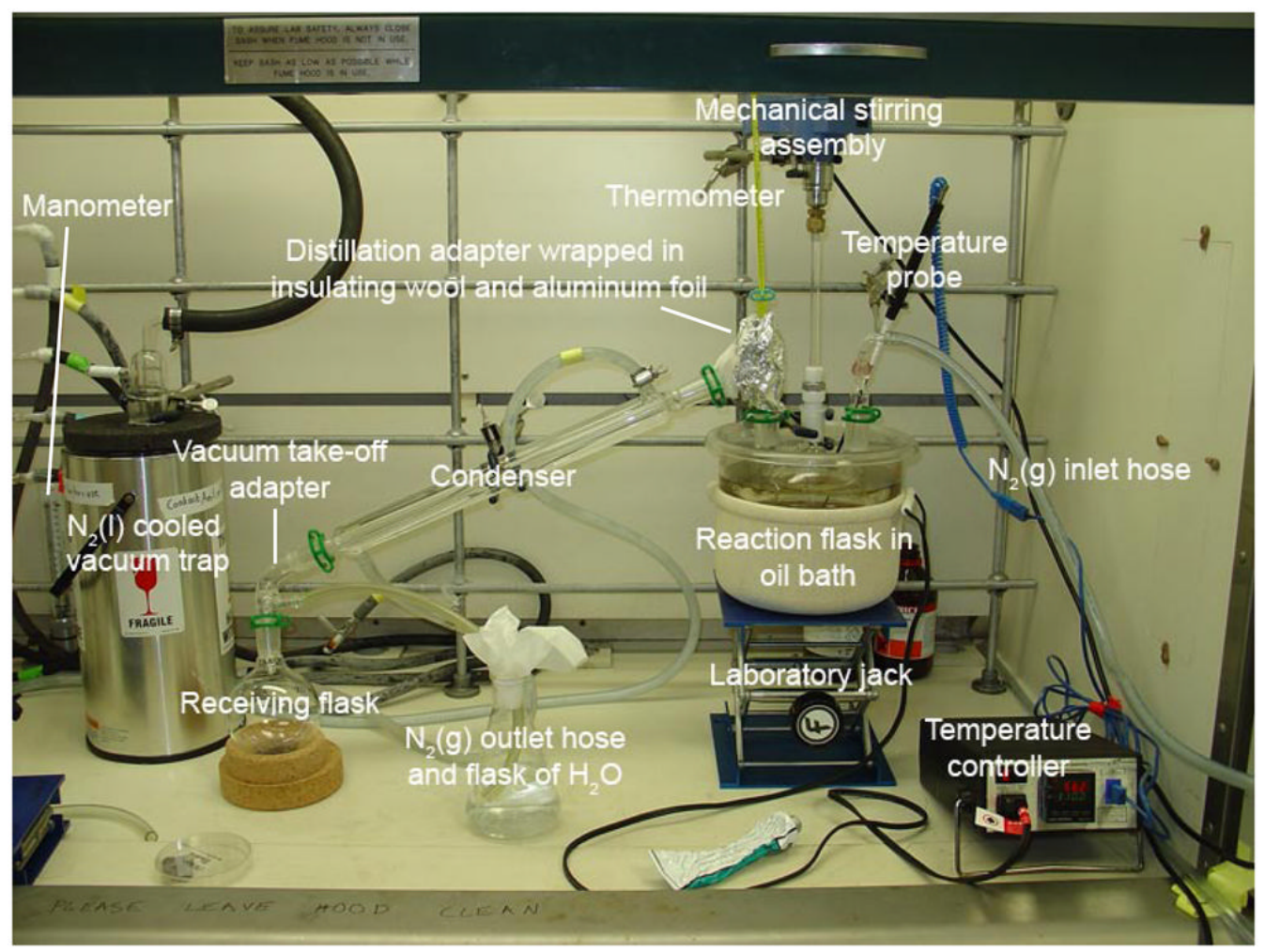

Figure 2.

Apparatus for PPF synthesis. Note that the apparatus is the same for the Steps $1-9$ and Steps $10-20$, with one exception. In Steps $10-20$, the $\mathrm{N}_{2}(\mathrm{~g})$ outlet hose attached to the outlet access port of the vacuum take-off adapter (used in Steps $1-9$ ) is replaced by a hose connecting the vacuum take-off adapter to a high vacuum source with an associated vacuum trap. 


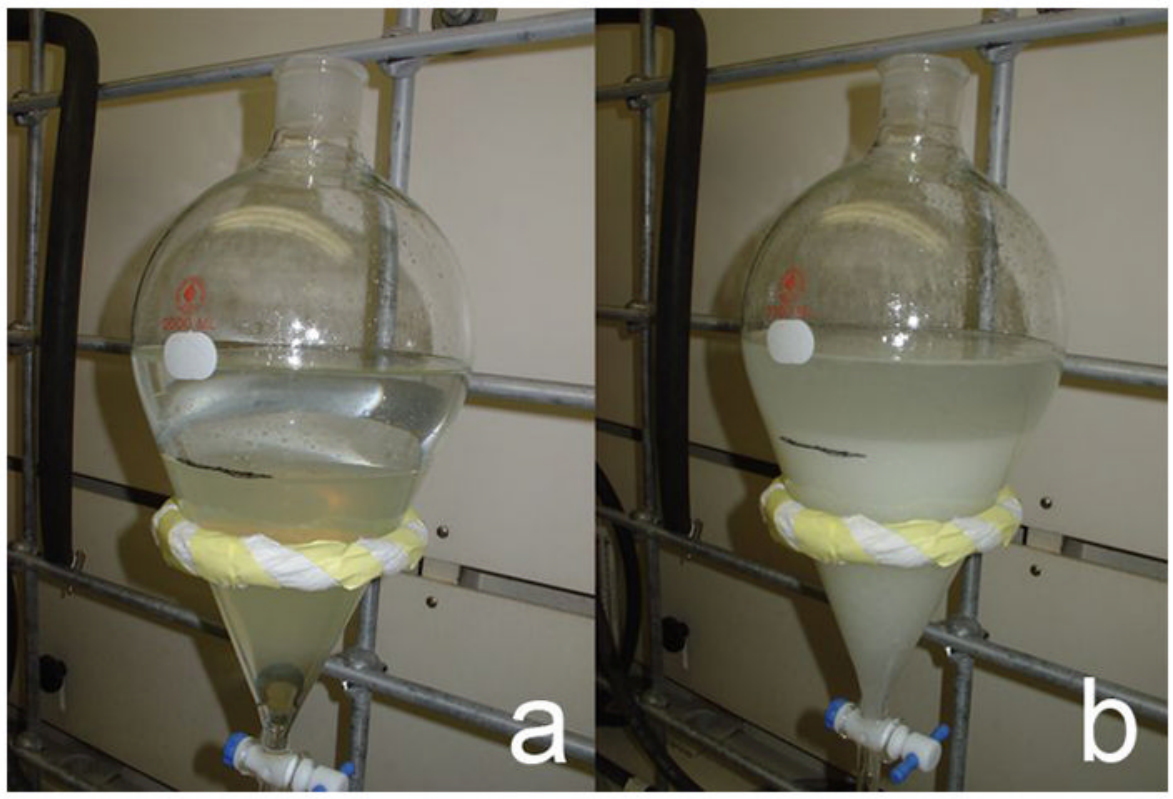

Figure 3.

Washing of PPF solution during product purification. The PPF phase appears as the bottom phase and $\mathrm{HCl}$ solution appears as the top phase (A) prior to agitation and (B) following a settling period after agitation. 


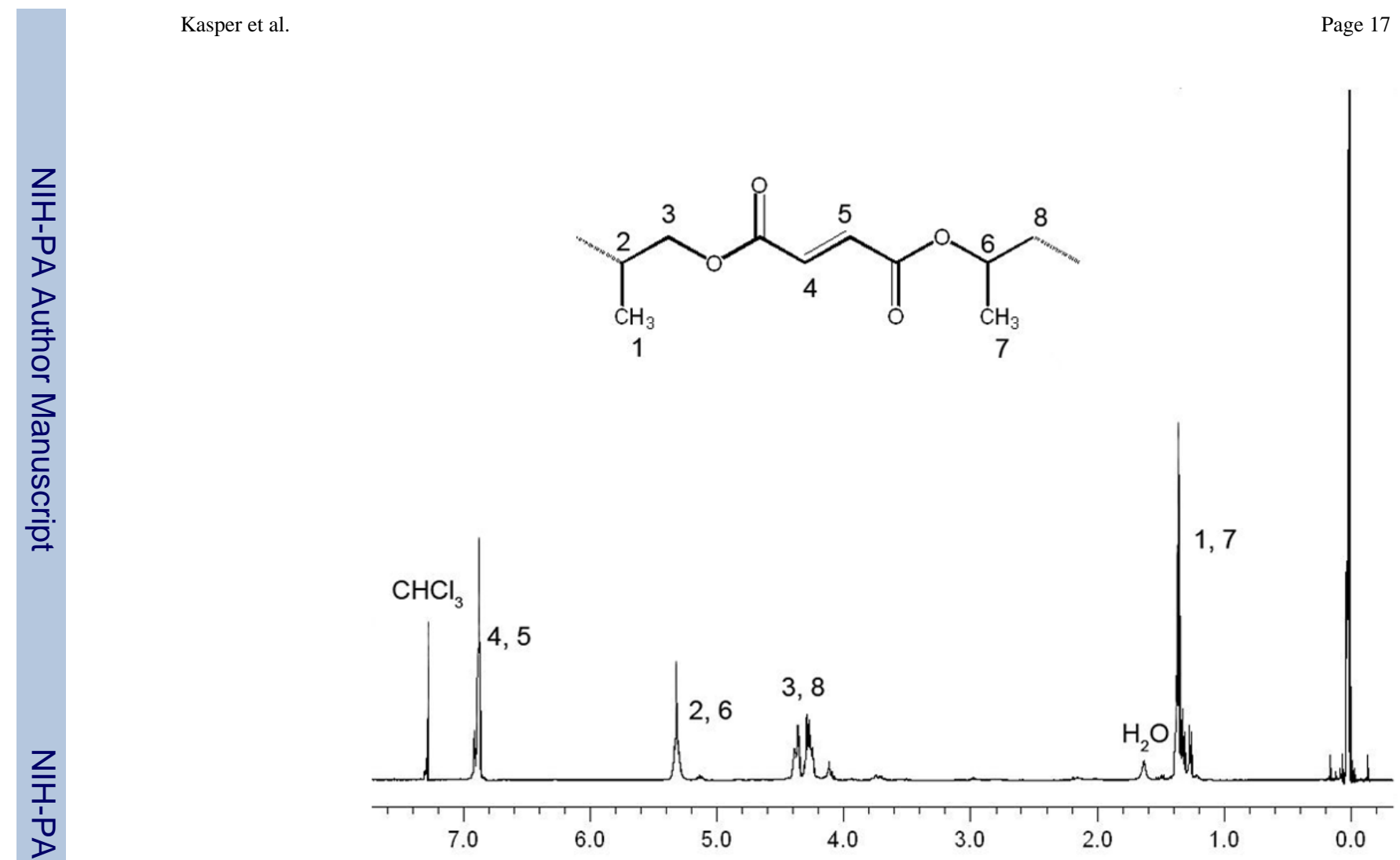

Figure 4.

A typical ${ }^{1} \mathrm{H} \mathrm{NMR}\left(400 \mathrm{MHz}, \mathrm{CDCl}_{3}\right.$, ambient temperature) spectrum of purified PPF. 


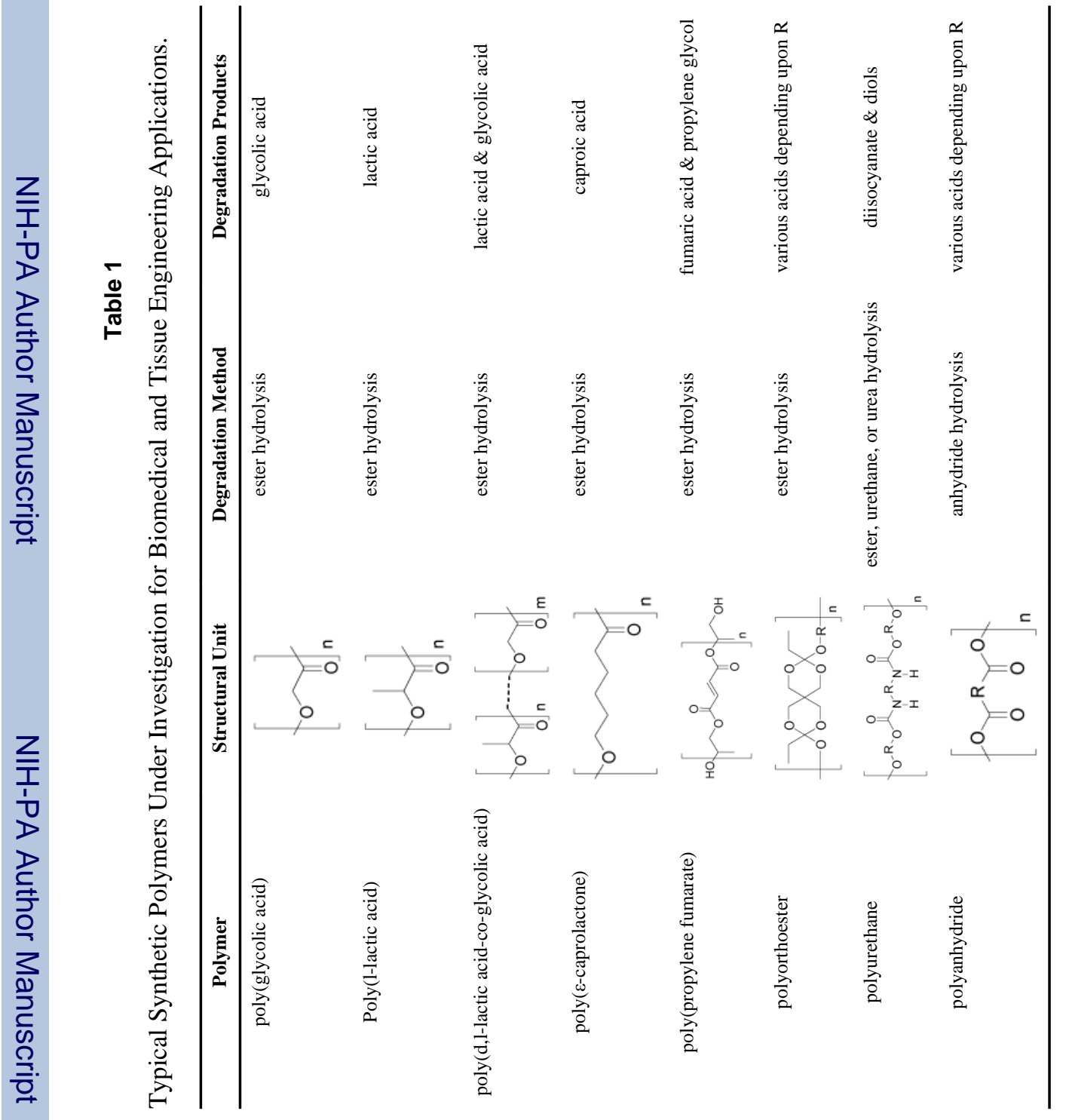


Table 3

Troubleshooting Table.

\begin{tabular}{|c|c|c|}
\hline Problem & Step & Solution \\
\hline Slow reaction kinetics & 8 & $\begin{array}{l}\text { Increase reaction temperature up to } 150^{\circ} \mathrm{C} \text {, increase stirring rate, and/or increase } \mathrm{N}_{2}(\mathrm{~g}) \text { purge rate; } \\
\text { ensure exclusion of } \mathrm{H}_{2} \mathrm{O} \text { from reaction system }\end{array}$ \\
\hline Slow reaction kinetics & 18 & $\begin{array}{l}\text { Increase reaction temperature up to } 150^{\circ} \mathrm{C} \text {, increase stirring rate, and/or increase } \mathrm{N}_{2}(\mathrm{~g}) \text { purge rate; } \\
\text { ensure exclusion of } \mathrm{H}_{2} \mathrm{O} \text { from reaction system }\end{array}$ \\
\hline Low molecular weight & 19 & $\begin{array}{l}\text { Increase the reaction temperature and/or duration of the reaction; ensure exclusion of } \mathrm{H}_{2} \mathrm{O} \text { from } \\
\text { reaction system }\end{array}$ \\
\hline High molecular weight & 19 & Decrease the reaction temperature and/or duration of the reaction \\
\hline $\begin{array}{l}\text { Three-phases in purification } \\
\text { washes }\end{array}$ & 29 & $\begin{array}{l}\text { Decrease the intensity of agitation during the aqueous washes and/or add a small volume }(\sim 50 \mathrm{ml}) \\
\text { of brine to the aqueous phase }\end{array}$ \\
\hline
\end{tabular}

